\title{
Lever holding behavior during a leverlift shock escape procedure*
}

\author{
HANK DAVIS, PAUL HIRSCHORN, and HARRY M. B. HURWITZ \\ Eniversity of Guelph. Guelph, Ontario. Canada
}

\begin{abstract}
Rats were trained either to press a lever or to lift a lever in order to escape shock. Although there were no appreciable differences between escape latencies. the leverlift condition eliminated virtually all of the intertrial lever holding observed under the leverpress condition. While stable escape behavior can be obtained using either the press or lift responses. the use of a leverlift requirement allows for the separate observation of lever holding and freezing. a species-specific defense reaction.
\end{abstract}

A common method for studying escape behavior is to require the $\mathrm{S}$ to make a single leverpress response in order to terminate shock (e.g., Dinsmoor \& Hughes. 1956). Despite its relative simplicity, this requirement typically yields nothing approaching the behavioral economy of a single depression of the lever. Instead. shock escape procedures generate spurious or "extra" behavior as characteristically as they generate the escape response itself. Moreover. these additional responses fall into predictable categories, the most prevalent of which is described as "lever holding." This behavior typically begins with a lever depression almost immediately following shock onset. The low-latency escape response is then followed by the S's continued depression of the lever throughout most or all of the shock-free intertrial interval, ${ }^{1}$ until the next shock is presented. The $S$ then emits the next escape response and the holding sequence begins again. Lever holding during escape conditioning has been shown to persist in spite of the imposition of a punishment contingency (Migler, 1963b) and the addition of a lever-release requirement (Dinsmoor. Hughes, \& Matsuoka. 1958).

Whereas lever holding behavior was previously viewed as an experimental annoyance (e.g.. Dinsmoor \& Hughes. 1956), it has since been acknowledged as such a pervasive phenomenon as to warrant independent investigation (e.g.. Campbell, 1962). To date. the explanation of lever holding behavior during escape conditioning has involved one of the following theoretical analyses:

The preparaton response argument (Dinsmoor. Matsuoka, \& Winograd, 1958) is based on the fact that Ss escape shock more rapidly on those trials in which they are positioned on the lever at shock onset, in comparison to trials in which the $S$ is off the lever when the shock begins (Campbell. 1962). This advantage in

\footnotetext{
*The authors wish to thank J.D. Keehn for his suggestions and critical evaluation of the manuscript. This research was supported in part by Grant No. A8264 from the liational Research Council of Canada to H. .. B. Hurwitz and by a grant to Hank Davis from the lniversity of Guelph Research Advisory Board. Reprints may be obtained irom Hank Daris. Department of Pyychology. Lniversity of Guelph. Guelph. Ontario. Canadit.
}

minimizing shock serves to reinforce the holding response, which may be viewed as "preparation" for leverpress escape. The preparatory view received further support, albeit indirect, from Marriott and Russell (1969). who showed that rats that held the lever during traditional escape ceased to do so when lever holding no longer produced a preparatory advantage under a two-lever discriminated escape procedure.

A recent experiment by Keehn (1967), however. has dealt the preparatory argument considerable harm. Although Keehn's procedure involved both escape and avoidance components, his data bear directly on the notion of "preparation" as a strategy for escape. Employing a two-lever procedure. Keehn required his Ss first to press Lever $\mathrm{A}$ and then Lever $\mathrm{B}$ in order to terminate shock. He argued that because of the additional response requirement ideal preparation should involve holding of Lever A. Because his Ss consistently held Lever B. Keehn interpreted his data against the preparatory argument and in favor of the notion of perseleration. The perseveration argument (Keehn. 1967) assumes that behavior occurring at the moment of reinforcement is strengthened and becomes a predominant feature of the Ss' performance. In the case of leverpress escape. lever holding would persist because of its topographical similarity to the behavior that has just terminated shock. Thus. Keehn's report that Lever B was held. despite the fact that it impeded preparation for escape. would seem to strengthen the notion of perseveration.

Most recently: an argument has been advanced by Bolles (1970) and Bolles and McGillis (1968) that stresses the role of species-specific defense reactions (SSDR) in maintaining lever holding in the rat. as well as in accounting for escape behavior itself. When flight from the shock situation is not possible. the rat tends to freeze (an SSDR) at the moment shock is terminated. Under the leverpress escape procedure. this. of necessits. places the animal on the lever. albeit "accidentally" at first. Any alternative behavior. such as movement away from the lever. is "punished" by shock. which continues to be delivered until the rat returns to and presses the 
Table 1

Escape Performance Recorded Inder Procedure Which Required $S$ to Lift Lever to Terminate Shock and Under Traditional Leverpress Escape Procedure*

\begin{tabular}{|c|c|c|c|c|c|}
\hline & \multirow[b]{2}{*}{$\mathrm{S}$} & \multicolumn{3}{|c|}{ Training Sessions } & \multirow{2}{*}{$\begin{array}{c}\text { Extinction } \\
\text { Total } \\
\text { Lever } \\
\text { Holding } \\
\text { (in Sec) }\end{array}$} \\
\hline & & $\begin{array}{l}\text { Percent } \\
\text { of } \\
\text { Shocks } \\
\text { Escaped }\end{array}$ & $\begin{array}{c}\text { Mean } \\
\text { Escape } \\
\text { Latency } \\
\text { (in Sec) }\end{array}$ & $\begin{array}{c}\text { Percent } \\
\text { Lever } \\
\text { Holding; } \\
\text { Session }\end{array}$ & \\
\hline \multirow{6}{*}{$\begin{array}{l}\text { Lever- } \\
\text { Lift } \\
\text { Group }\end{array}$} & L2 & 100 & 1.27 & 2 & 76 \\
\hline & L5 & 100 & .53 & 7 & 24 \\
\hline & L6 & 100 & .76 & 2 & 18 \\
\hline & L7 & 100 & .50 & 9 & 50 \\
\hline & $L 8$ & 100 & .79 & 15 & 241 \\
\hline & L9 & 100 & .66 & 4 & 3 \\
\hline \multicolumn{2}{|c|}{ Group Mean } & 100 & .75 & 6.5 & 68.6 \\
\hline \multirow{6}{*}{$\begin{array}{l}\text { Ierer- } \\
\text { Press } \\
\text { Group }\end{array}$} & P1 & 100 & .93 & 88 & 1348 \\
\hline & $\mathrm{P} 2$ & 100 & .74 & 79 & 1092 \\
\hline & $P \vdots$ & 100 & .62 & 92 & 671 \\
\hline & $\mathrm{P4}$ & 100 & .66 & 94 & 680 \\
\hline & PS & 100 & .71 & 79 & 861 \\
\hline & P6 & 100 & 1.16 & 81 & 848 \\
\hline \multicolumn{2}{|c|}{ Group Me.an } & 100 & .80 & 85.5 & 916.6 \\
\hline
\end{tabular}

* Data ari from final fitre conditioning sessions and a single ¿-h extinction session

lever. It is. therefore. not surprising that Ss remain frozen upon the lever between shock deliveries for the majority of the escape session (Migler. 1963a). Bolles and McGillis account for recorded leverpress escape responses as momentary breaks in the lever holding sequence caused by ".... either a reflexive lurch (to shock onset) or perhaps a direct current-induced muscular contraction that results in the bar being released and depressed [1968,p. 261]."'

Although the SSDR notion is an appealing view that seems to integrate much data (e.g., Bolles, 1970, 1971), it remains problematic insofar as freezing, an SSDR, is not typically distinguished from holding in the conventional leverpress situation. That is, as long as lever holding can occur for reasons other than freezing (e.g., preparation). the standard leverpress requirement does not allow for an adequate assessment of the SSDR position.

In the following experiment, a unique response requirement is employed during an otherwise conventional schedule of shock escape. This requirement allow's for the separate observation of freezing (immobility) and lever holding. The rat is required to lift rather than to press a lever in order to terminate shock. The results of this response requirement can be compared directly to escape data from an identical situation involving a standard leverpress requirement equated for response force. In making this comparison, "holding" under the leverlift condition will be defined as sustained bodily contact with the lever in a lifted or operated position. The outcome of this comparison may bear directly on the role of SSDRs (specifically. freezing) in maintaining lever holding, as well as shed evidence on the perseverative analysis of lever holding during leverlift escape.

\section{METHOD}

\section{Subjects}

Fifteen male albino rats, approximately 90 day's old. served as Ss. Ss were individually caged. with food and water freely available in their home cages.

\section{Apparatus}

Ss were run in one of two identical grid shock chambers that measured $12 \times 9 \times 7 \%$ in. high. Side chamber walls were constructed of clear Plexiglas. Electric shock set at $4 \mathrm{~mA}$ was provided by a constant-current shock generator and scrambler and delivered to the floor grids, rear cage wall, and lever. Levers in both cages were made of metal and protruded 1 in. from the center of the front cage wall, 2 in. above the grid floor. In the cage used for the leverpress procedure. operation of the lever required a minimum of $12 \mathrm{~g}$ downward force to operate. The lever in the second cage. employed for the leverlift procedure. required a minimum of $12 \mathrm{~g}$ upward force to operate the microswitch. In addition to equating the force required to operate either lever. further assurance that the responses may be regarded as equivalent and symmetrically opposite comes from observation of the Ss under the leverlift procedure. All Ss merely positioned themselves beneath the lever and did little actual "work" in meeting the response requirements (see Results).

\section{Procedure}

Ss were divided randomly into either the leverlift or leverpress group. Sample size was set at six for each group, although nine animals were required to produce six trained $S s$ to criterion under the leverlift procedure. Escape training consisted of an initial manual shaping session. during which the $S$ was familiarized with the apparatus and given preliminary shock escape training to an arbitrary criterion of 10 consecutive low-latency $(<1 \mathrm{sec})$ escape responses. Ss under both conditions were then run for 15 dajly escape sessions, during which 50 4-mA shocks were programmed to occur $1 \mathrm{~min}$ apart from offset to onset. Finally, all Ss were exposed to a single 5-h extinction session, during which shocks were withheld.

In addition to behavioral observations during both conditioning and extinction sessions, recordings were made of each S's escape latencies and the percentage of session time spent in holding the lever in an activated (i.e.. downward or upward for the leverpress and -lift groups, respectively) position.

\section{RESULTS}

The results of the experiment are given in Table 1. Ss in the leverpress group readily met the training criterion within a relatively brief period, averaging $30 \mathrm{~min}$ and 35 shock deliveries, whereas training the leverlift escape response was more difficult, taking an average of $90 \mathrm{~min}$ and 90 shocks. Nevertheless, Ss under both conditions learned to escape shock and, with the exception of the lever holding data, there were no differences in performance attributable to the leverlift vs leverpress manipulation. Conditioning data, collected when performance had stabilized after 10 sessions. reveal that Ss under the "traditional" leverpress procedure showed a far greater tendency 10 hold the lever $(\bar{X}=85.5 \%$ of the session) than did Ss under the leverlift manipulation $(\bar{X}=6.5 \%$ of the session). Moreover, this difference in lever holding was retained throughout the 5 -h extinction condition in the absence of shock (see Table 1). 
Although these data provide an accurate quantitative view of escape performance under the two conditions. they do nor indicate some essential differences in the underlying behavior. The leverlift response was typically accomplished by the S's positioning itself under the lever and thrusting its back upward into contact with the lever at shock onset. Ss in the leverlift group typically remained frozen under, but not in contact with. the lever between shock deliveries. No S learned to use its paws in executing the leverlift response, although several Ss actually made abortive paw press responses and held the lever depressed early in the leverlift training.

Whereas leverpress trained Ss showed consistent escape performance throughout the 15 experimental sessions, all Ss under the leverlift condition occasionally produced long-latency escape responses. During such periods, Ss appeared "disoriented" and traversed the perimeter of the cage making thrusting responses with their backs, similar in topography to successful escape responses but differing only in the area of the cage in which they occurred.

\section{DISCUSSION}

At the simplest and least surprising level, the present experiment has demonstrated that escape behavior is not restricted to the leverpressing response requirement most generally employed.

At a second level of analysis. it also appears that. without affecting escape efficiency, the leverlift requirement has minimized lever holding, a feat not readily accomplished with previous operational changes (Migler. 1963b: Dinsmoor. Hughes. \& Matsuoka. 1958). This result, however. is directly tied to the fact that the leverlift procedure has for the first time separated lever holding from its underlying component: freezing. That is. all Ss still showed extensive freezing between shock deliveries. but the freezing occurred under the lever rather than on it. In showing that the amount of lever holding may drop dramatically while freezing per se remains as dominant as it ever was, these results support the analysis of escape behavior that stresses the importance of species-specific defense reactions (Bolles \& McGillis. 1968: Bolles. 1970).

Previous experimental work (Keehn. 1967) has disputed preparation as an explanation for lever holding. The question remains whether perseveration provides a better account of the extensive lever holding observed during shock escape than does the more recently formulated SSDR notion. Data from the present experiment bear directly upon this question. Under the leverlift condition. the behavior immediately contiguous with shock termination must. of necessity' have involved bodily contact with the lever. However. in direct conflict with the perseverative argument. no leverlift $S$ in the present experiment gave any evidence of such sustained contact with the lever between shock deliveries. The fait that freezing under the lever was widels observed for all leverlift animals does. however. offer direct support for the SSDR notion.

Ironically. the results of the present experiment are also compatible with the previously contested preparatory response notion. That is. given the nonmanual topography employed by all Ss under the leverlift condition, it may be just as "preparatory" in terms of minimizing shock to wait immobile under the lever for shock to begin as it is to hold the lever down under traditional leverpress escape. This "support." as it were. for a previously "defeated" hypothesis points out a difficulty in the way each of these alternative positions is stated. It may well be that no single experiment can serve as an ultimate critical test between all three positions. Rather, it may be that several experiments taken in tandem are necessary to resolve the issue. For instance, when the results of the experiment by Keehn (1967) are considered along with the present data, it becomes clear that the SSDR notion is most tenable. Specifically, Keehn's data dispute the preparatory argument and support the perseveration notion. However. Keehn's results are also completely compatible with the SSDR position; that is, when a $S$ freezes upon Lever $B$ in a two-lever situation, he may, rather than "perseverating" at Lever B, simply have been freezing at the moment of shock offset, which, perforce, would guarantee his being on Lever B. Thus, it appears that the SSDR argument is supported by data from both Keehn's study and the present experiment: whereas both the preparatory and perseverative notions are in conflict with the results of one or the other of these studies.

The probable interdependence of innate factors and operant learning in generating what we simplistically label "escape behavior" supports a growing awareness of the inadequacy of a total dependence on the law of effect. Alternatives to the purely operant analysis have been suggested not only by Bolles (1970) and Bolles and McGillis (1968) but also by Breland and Breland (1966) and by Seligman (1970). In line with these analyses and because freezing may be as adaptive in the escape conditioning situation as it is in the natural environment. it seems as important to watch our Ss during escape conditioning as it is to watch our counters.

\section{REFERENCES}

Bolles. R. (. Species speciric defense reactions and avoidanic conditioning. Psychologival Review, 1970. 77. 32-48.

Bolles. R. C. Species-specific defense reactions. In F. R. Brusht IEd.l. Alersile conditioning and learming. lew York: Academic Press. 1971

Boll's. R. C. \& MeGillis. D. B. The nonoperant nature of the barpress escape response. Psychonomic Science. 1968. 11. 261-26?

Breland. K.. \& Breland. II. Animal behavior. lew Jork Macmillan. 1966.

Campell. S. L. Lever holding and behasior sequenes in thoik cicape. Journal of Compartice \& Physologrical Pusholos! $1902.55 .1047-1053$

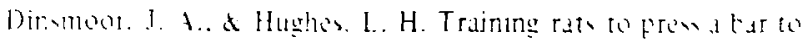


turn off shock. Journal of Comparative \& Physiological Psychology. 1956. 49. 235-238.

Dinsmoor. I. A., Hughes, L. H.. \& Matsuoka. $Y$. Escape-from-shock training in a free-response situation. American Journal of Psychology. 1958. 71, 325-337.

Dinsmoor. J. A.. Matsuoka. Y.. \& Winograd, E. Bar-holding as a preparatory response in escape-from-shock training. Journal of Comparative \& Physiological Psychology. 1958. 51. 637-639.

Keehn. J. D. Is bar-holding with negative reinforcement preparatory or perseverative? Journal of the Experimental Analysis of Behavior. 1967. 10. 46 1-465.

Marriott. A. S. \& Russell. I. S. Lever-holding and the operant nature of escape responding. Psychonomic Science. 1969. 15. 1-2.

Migler. B. Bar-holding ưring escape conditioning. Journal of the Esperimental Analysis of Behavior. 1963a. 6.65-74.

Migler. B. Experimental self-punishment and supertitious escape hehatior. Joumal of the Experimental Analysis of Behavior. 1963b. 6. 371-385.
Seligman. II. E. P. On the generality of the laws of learning. Psychological Review, 1970.77. 406-418.

Walsh. M.. \& Keehn. J. D. Avoidance behavior in a bar-pressing situation as a function of release shock intervals. Psychological Reports. 1969. 24. 511-518.

\section{NOTE}

1. Walsh and Keehn (1969) have shown that the degree of intertrial bar holding, at least in avoidance situations, may be dependent upon the duration of the intertrial interval.

(Received for publication February 2, 1973; revision received May 3, 1973; accepted May 7. 1973.) 